\title{
FILOSOFIA DA EDUCAÇÃO NO PERÍODO MEDIEVAL
}

\author{
Philosophy of Education in Medieval Period
}

\author{
Antonio Djalma Braga Junior ${ }^{1}$ \\ Ivanildo Luiz Monteiro Rodrigues dos Santos ${ }^{2}$
}

\begin{abstract}
RESUMO: Sabe-se que todo o pensamento no período da era medieval estão conectados de uma forma ou outra com o grande debate entre $F e ́$ e Razão. Vários foram os autores que procuraram conciliar ou abrir ainda mais o abismo entre estes dois conceitos. $\mathrm{O}$ acontecimento decisivo neste período foi a apropriação do termo Logos pelo cristianismo que passa a partir de então não mais a fazer uma teologia, mas também uma reflexão filosófica. Diante desse cenário, o presente artigo tem como objetivo apresentar uma filosofia da educação no período medieval a partir da análise de alguns textos clássicos escritos nesse período histórico. Nessa perspectiva, pretende-se compreender a problemática da formação humana no medievo através de concepções éticas e políticas, bem como a influência de tais ideias no campo da educação. Para atingir este intento, utilizaremos como base principalmente os textos de autores como Bernardo de Claraval, São Boaventura, Hugo de São Vítor e Tomás de Aquino. Espera-se que ao fim desse artigo reste clara a importância desses autores para delinearmos uma filosofia da educação durante o período medieval, de modo que os pré-conceitos que ainda persistem em evocar a expressão "idade das trevas" sejam deixadas de lado para reconhecermos a imensa riqueza que perpassa os mais variados campos do conhecimento no medievo, inclusive a área da filosofia da educação.
\end{abstract}

PALAVRAS-CHAVE: Filosofia da Educação; Filosofia Medieval; Fé; Razão; Educação.

ABSTRACT: It is known that all thought in the period of the medieval era is connected in one way, or another, with the great debate between Faith and Reason. Several authors tried to reconcile or open the gap between these two concepts even further. The decisive event in this period was the appropriation of the term Logos by Christianity, which, from then on, no longer does a theology, but also a philosophical reflection. Given this scenario, the present article aims to present a philosophy of education in the medieval period from the analysis of some classic texts that were written in that historical period. In this perspective, it is intended to understand the problem of human formation in the Middle Ages through ethical and political conceptions, as well as the influence of such ideas in the field of education. To achieve this goal, we will mainly use the texts of authors such as Bernard of Clairvaux, Saint Bonaventure, Hugh of Saint Victor and Thomas Aquinas. It is hoped that at the end of this article, the importance of these authors to clarify a philosophy of education during the medieval period remains clear, so that the

\footnotetext{
${ }^{1}$ Doutor em filosofia pela Universidade Federal do Paraná (UFPR) e professor na Universidade Positivo (UP). E-mail: antonio.djalma@hotmail.com

${ }^{2}$ Doutorando em filosofia pela Universidade Federal do Paraná (UFPR) e professor na Secretaria de Estado da Educação do Paraná (SEED-PR). E-mail: ivanluiz.m@gmail.com
} 
preconceptions that still persist in evoking the expression "dark ages" are left aside to recognize the immense wealth that permeates the most varied fields of knowledge in the Middle Ages, including the area of the philosophy of education.

KEYWORDS: Philosophy of Education; Medieval Philosophy; Faith; Reason; Education.

Sabe-se que todo o pensamento no período da era medieval estão conectados de uma forma ou outra com o grande debate entre Fé e Razão. Vários foram os autores que procuraram conciliar ou abrir ainda mais o abismo entre estes dois conceitos. $\mathrm{O}$ acontecimento decisivo neste período foi a apropriação do termo Logos pelo cristianismo que passa a partir de então não mais a fazer uma teologia, mas também uma reflexão filosófica.

Diante desse cenário, o presente artigo tem como objetivo apresentar uma filosofia da educação medieval a partir da análise de alguns textos clássicos escritos nesse período histórico. Nessa perspectiva, pretende-se compreender a problemática da formação humana no medievo através de concepções éticas e políticas, bem como a influência de tais ideias no campo da educação.

Para atingir este intento, utilizaremos como base principalmente os textos de Bernardo de Claraval intitulado o Sermão sobre o conhecimento e a ignorância, escrito por volta dos séculos XI e XII; o Tratado sobre a redução das Ciências à Teologia, de São Boa Ventura; a obra de Hugo de São Vítor, Didascalion: da arte de ler; juntamente com o De magistro (sobre o ensino) e a questão 117 da Suma Teológica de Tomás de Aquino, que trata da questão acerca da ação do homem.

Espera-se que ao fim desse artigo, reste clara a importância desses textos, autores e conceitos para delinearmos uma filosofia da educação durante o período medieval, de modo que os pré-conceitos que ainda persistem em evocar a expressão "idade das trevas" seja deixada de lado para reconhecermos a imensa riqueza que perpassa os mais variados campos do conhecimento inclusive a área da filosofia da educação.

\section{Bernardo de Claraval}

Para pensarmos em uma Filosofia da Educação dentro do pensamento de Bernardo de Claraval, precisamos ter em conta que este é um autor singular, pois no inicio do século XII, aos vinte anos de idade, vindo de uma família nobre, ele deixa sua educação de cavaleiro, para, juntamente com mais quatro irmãos e 25 amigos, entrar no mosteiro de Cister, que havia sido fundado "para ser um mosteiro de reforma, como um mosteiro que 
resgatasse o autêntico espírito monástico cristão contra a tendência sempre usual, ao longo da história do cristianismo, à acomodação, à desvirtuação pelo relaxamento"3 . Após ter sido enviado, com apenas 24 anos, para fundar o mosteiro de Claraval, Bernardo se revelou um grande personagem do cristianismo, chegando a fundar mais de oitenta novos mosteiros sob sua tutela, produzindo ao mesmo tempo uma rica bibliografia teórica, homilética e mística, se destacando sempre como um homem extremamente contemplativo.

A sua paixão, leva-o a pensar sobre as questões referentes ao conhecimento humano. Em seu Sermão sobre o conhecimento e a Ignorância, Bernardo de Claraval descreve que:

Há quem busque o saber por si mesmo, conhecer por conhecer: é uma indigna curiosidade. Há quem busque o saber só para poder exibir-se: é uma indigna vaidade. Estes não escapam à mordaz sátira que diz: teu saber nada é, se não há outro que saiba que sabes. (...) Há quem busque o saber para vendê-lo por dinheiro ou por horas: é um indigno tráfico. Mas há quem busque o saber para edificar, e isto é amor. E há quem busque o saber para se edificar, e isto é prudência ${ }^{4}$.

Em suma, precisamos conhecer as coisas não somente para conhecer, pois esta seria um indigna curiosidade, mas precisamos conhecer as coisas com amor, para podermos edificar e, ainda para se edificar - pois esta seria uma prudência necessária para vivermos. Deste modo, ao adentrarmos mais à fundo na obra de Bernardo, precisamos compreender alguns pontos referentes ao período histórico no qual ele está ambientado.

Primeiramente é importante saber que os pedagogos modernos são mais cruéis com as crianças do que os de antes, pois eles se baseiam em uma pedagogia da disciplina, que é recuada à idade que, a partir da qual, começa se pensar racionalmente a questão do nascimento da criança. Para ilustrar tal idéia, vale lembrar que os homens, Roma, até os 7 anos de idade, ficava com a mãe e somente depois disso, a mãe não podia mais vê-lo. Ele enfrentaria uma educação militar, viraria um soldado. A partir dos cuidados de um tio, ele começava a participar de uma hierarquia social bem definida. Deste modo, até os 7 anos não há nenhuma referência de educação, ele faz o que quer, sendo cuidado exclusivamente pela mãe. Tal concepção percorreu durante a idade média, onde a educação acontece principalmente nos mosteiros e a aceitação na vida monacal acontece a partir dos 7 anos, não havendo, antes, nenhum indício de educação.

\footnotetext{
${ }^{3}$ LAUAND, L. J. Cultura e educação na Idade Média. São Paulo: Martins Fontes, 1998, p. 255.

${ }^{4}$ LAUAND, L. J. Cultura e educação na Idade Média. São Paulo: Martins Fontes, 1998, p. 256.
} 
Em um segundo momento, é importante ressaltar que as fontes que falam sobre as crianças são mais prescritivas do que descritivas e todo e qualquer tratado pedagógico são espécies de micro utopia, no sentido de descrever o que as crianças devem fazer em cada etapa da vida. Os tipos de documentos que falam sobre isso são as crônicas, os manuais para confessores - esses tipos de documentos permitem inferências - documentos judiciais (disputas judiciais), testamentos dos pais que morrem quando os herdeiros são ainda crianças e registros de capítulos e guildas.

Há textos que afirmam que as crianças são seres fracos, idiotas (no sentido grego, de que não entrou na vida pública, capaz de ter uma vida social autônoma) e que a criança quando nasce não é portadora daquilo que a define como um ser humano (capacidade da fala, de usar a razão) - a prova disso é que se você abandonar uma criança, ela não consegue sobreviver. Já outros textos afirmam que as crianças possuem uma potência humana, que se não for desenvolvida, se perderá, por isso precisa de uma educação para desenvolver esta potência. O ser humano é algo que requer uma construção - para falar em termos aristotélicos. Outros textos afirmam ainda que as crianças são dotadas de desejo e, por isso, até os 7 anos elas são incapazes de pecar.

As etapas da infância (até os 7 anos) que estão aceitos em quase todos os textos têm sua origem entre os romanos e são vistos à luz dos problemas de mortalidade infantil da época. A próxima fase vai dos 7 anos até os 14 anos, onde se inicia a sexualidade - fase da pueridade. A infância é própria da fase do "falar", já esta segunda fase é própria da pueridade, pois começa desenvolver a capacidade de escolher o bem o mal e por isso já pode fazer escolhas, mentir, roubar, e cometer atos sexuais. Bartholomaeus Anglicus, pensador que viveu após Bernardo de Claraval, escreveu livros sobre as propriedades das coisas. Em um texto intitulado De Pueri, ele descreve esta fase da pueridade, afirmando que as crianças desta idade são descuidados e vivem no presente, prefere jogos e brincadeiras com os seus iguais; essas crianças são totalmente inacessíveis aos elogios e só o castigo funcionam; ao mesmo tempo, estas crianças vêem o castigo como a pior coisa que podem acontecer, elas passam rapidamente de um sentimento para outro - do ódio ao amor - e são crianças que não guardam segredos, ficam quietos somente quando estão dormindo; elas cobiçam qualquer coisa que aparece na frente e ficam sempre gritando, se sujam e detestam tomar banho; são muito flexíveis, mas não suportam doenças; elas dormem demais e estão sempre com fome. As palavras de Bartholomaeus Anglicus são descritivas, um dos poucos textos descritivos deste período. 
A partir dos 14 anos, a pessoa passa para uma educação de caráter mais intelectual. As atividades deste período exigiriam uma capacidade intelectual mais organizada. Os 14 anos, na vida dos camponeses, marcam o ingresso da vida no campo, aqueles que não iriam ingressar na vida monástica, nem na vida política, nem ser médico, iriam trabalhar. Esta fase, segundo alguns pensadores, ia até os 25 anos, onde chegaria à idade da Juventus (Juventude).

No que tange as diferenças entre meninos e meninas, cabe ressaltar que não há distinções na fase da infância. Na puberdade, estas diferenças seriam tratadas isoladamente, separados, sendo que a educação do menino era a prioridade.

Na discussão da adolescência, a proporção de textos e discussões sobre as meninas, é muito mais escasso ainda, donde se pode concluir que elas eram educadas para funções especificas mais simples na sociedade. As meninas, em geral, não chegam na educação formal e não podiam atingir funções eclesiástica.

O ócio em Roma era para ser dedicado às coisas não-públicas, era para ser usada nas suas coisas privadas. O indivíduo que está no ócio é um indivíduo que está livre para as artes literárias, para poder estudar o ensino que abarca a totalidade da formação humana (enciclopédia: ensino da Paidéia) que visava a dar uma educação daquilo que constitui a humanidade, que torna o indivíduo um ser humano.

Os estudos de formação intelectual neste período medieval compreendiam os cursos do Trivium e Quatrivium. Enquanto no primeiro, o indivíduo aprenderia a ler e a escrever, no segundo ele aprenderia a pensar naquilo que ele estava escrevendo e lendo. Aprenderia a estrutura da fala, os casos, o bom advogado seria aquele então que saberia dominar uma técnica capaz de convencer qualquer público.

Diante deste cenário, Bernardo de Claraval, no sermão 36, propõe-se a falar sobre a ignorância de si mesmo e a ignorância de Deus. Ainda que Bernardo seja um místico, partidário fervoroso da fé, ele acreditava que a ignorância era um caminho de perdição. Ele dizia que a fórmula do saber viver é o conhecimento a Jesus crucificado: esta é a mais sublime Filosofia e a Pedagogia devia ensinar essa arte de viver.

Para isso "o primeiro passo, neste caminho, é precisamente o conhecimento de si mesmo que, sendo reto, é fruto e pressuposto da verdadeira humildade, virtude pela qual o homem se conhece a si mesmo verdadeirissimamente" ${ }^{\text {. }}$.

${ }_{5}^{5}$ LAUAND, L. J. Cultura e educação na Idade Média. São Paulo: Martins Fontes, 1998, p. 260. 
Em outras palavras, o conhecimento de Deus passa primeiramente pelo conhecimento de si mesmo. Isso porque um conhecimento deste tipo não nos torna arrogantes, mas ao contrário, nos humilha.

\section{Hugo de São Vítor}

A passagem do séc. XII para o XIII marca uma modificação das traduções. Aqui não temos nenhuma formação institucional formal, não há documentos que comprovem a organização formal das instituições que transmitiam conhecimento, nem fichas de inscrições, ou coisas do tipo. Isso começa somente com as universidades. Diante disso, algo que chama a atenção é que muitas ideias discutidas por Hugo de São Vitor são retomadas por Tomas de Aquino.

A obra Didascalion - da arte de Ler - escrito em 1127, precede a maioria dos outros textos de Hugo de São Vítor e é considerado um símbolo da efervescência desta época, sendo, ao lado de Dos Sacramentos, a obra mais importante em termos de racionalidade filosófica do período Vitorino. O da Arte de ler é de certo modo um currículo medieval dos estudos que procura incorporar o espírito das novas organizações religiosas da época procurando recapturar o ascetismo da Igreja primitiva. Os seus seis livros procuram demonstrar como o orat et labora compreende o método da obra, sendo que os três primeiros livros são dedicados ao conhecimento das coisas do homem pela leitura dos escritos literários e três dedicados ao conhecimento das coisas de Deus pela leitura da sagrada escritura.

Nesse artigo, limitaremos nossa análise somente aos livros 2, 3 e 6 da obra Didascalion, a fim de que não tornemos demasiada extensa a investigação sobre a formação humana no período medieval.

O livro II procura esclarecer as questões referentes à etapa de formação intelectual do homem a partir dos estudos do quatrivium, que compreende o estudo das artes como a teologia, matemática, as ciências mecânicas; e a lógica como os estudos do trivium.

O livro III procura dar subsídios aos jovens de como ler e o que ler, uma vez que ele afirma serem três as regras mais necessárias às leituras: "saber o que se deve ler, em que ordem se deve ler e como se deve ler" ${ }^{\text {. }}$

\footnotetext{
${ }^{6}$ HUGO DE SÃO VITOR Didascálion, Da arte de ler. Introdução e Tradução de Antônio Marchionni. Petrópolis: Vozes, 2001, p. 9.
} 
Ele indica neste livro quais foram os autores das artes, bem como, os mais ilustres representantes de algumas delas, estes que deram sequência aos ensinamentos de seus mestres - muitos dos quais, tem seu início entre os próprios deuses gregos ou de outros povos - e como discernir corretamente acerca do estudo, da meditação, da memória, disciplina, humildade, silêncio, despojamento e exílio.

Já no livro VI, Hugo de São Vítor procura argumentar que são três os modos de interpretação das Sagradas Escrituras: “interpretação histórica em sua ordem temporal (ordo temporis), interpretação alegórica segundo a ordem de conhecimento (ordo cognitions), interpretação antropológica (moral) com atenção às coisas mais importantes que as palavras, reflexões sobre os termos letra, significado, sentença e meditação"7.

Nessa perspectiva, se faz mister compreender que o ato de ler é seguido sempre, para Hugo de São Vítor, por um ato de ruminação, da mesma forma como os monges faziam com as sagradas escrituras durante os trabalhos manuais. Assim, é compreensível a afirmação de que a Sapiencia ilumina o homem e isso se efetiva a partir do conhece-te a ti mesmo, que passa a adquirir o discernimento para realizar as boas obras que o conhecimento se lhes clareou.

\section{São Boaventura}

Também chamado em sua época de Doctor Serephicus pertenceu à ordem franciscana em meados do século XIII e produziu uma rica bibliografia. Teve uma participação decisiva no concílio de Lyon onde, por amabilidade e mansidão, conquistou a admiração e a veneração de todos e dedicou-se com esmero em seu cargo de Ministro Geral da Ordem, tendo inclusive de renunciar às suas atividades acadêmicas.

O seu tratado sobre a redução das ciências à teologia, fora bastante difundido nos séculos passados. Nesta obra, afirma que cada ciência tem seu ponto de partida em algo que contenha um feixe de luz que conota algum conhecimento teológico e justamente por isso, todas elas estão orientadas pela Teologia, que é uma luz superior com a qual podemos conhecer a razão de ser de cada uma das ciências. A partir disso, Boaventura deseja que todas as ciências sejam postas a serviço do amor. Este deveria ser o fruto de todas as ciências.

\footnotetext{
${ }^{7}$ HUGO DE SÃO VITOR Didascálion, Da arte de ler. Introdução e Tradução de Antônio Marchionni. Petrópolis: Vozes, 2001, p. 29.
} 
A única forma, todavia, de se colocar em prática isto, é as ciências se subordinarem á teologia e deixar-se guiar por ela. Boaventura divide as ciências em quatro grandes grupos que as chama de iluminações.

Estas cuatro iluminaciones son: la luz exterior, o sea la de las artes mecânicas; la luz inferior, o sea la del conocimiento sensitivo; la luz interior, o sea la del conocimiento filosófico; la luz superior, o sea la de la gracia y Sagrada Escritura. La luz del conocimiento filosófico la subdvide em três diferencias o tonalidades: la luz de la filosofia racional, la luz de la filosofia natural y la luz de la filosofia moral ${ }^{8}$.

Deste modo, esta subdivisão das ciências que passam a ser chamadas de 6 iluminações por Boaventura, deve indicar a sua submissão à Teologia: todas estas iluminações ou grupos de iluminações estão subordinadas ao conhecimento teológico. Ele explica esta redução uma a uma em seu tratado: a iluminação sensitiva se reduz à teologia porque os cincos sentidos do corpo estão conformados segundo os cinco sentidos espirituais. Eles permitem conhecer uma tripla verdade: o Verbo encarnado no tempo, o conhecimento da vida eterna e a união de Deus com a alma; as artes mecânicas estão reduzidas à teologia de um modo análogo; a fillosofia racional, se reduz por conta de que ela nos dá a conhecer, também de forma análoga, a tripla verdade teológica através da palavra ou conceito expressado; a partir do intento de que as razões formais na matéria, na alma e na sabedoria divina, a filosofia natural se reduz á teologia, basta considerar estas coisas a partir do princípio de causalidade. Assim, fica claro que o conhecimento das coisas e das ciências que dela se deriva devem servir aos princípios teológicos e ter como base as sagradas escrituras e, em suma, é isso que deve ser prioriza em no processo de formação e educação dos homens.

\section{Tomás de Aquino}

A tese principal de Tomás de Aquino acerca de sua compreensão sobre aquilo que tange a educação desponta na Questão 117 da Suma Teológica, a saber, de que o homem é composto de alma e corpo, sendo que primeiramente "deve-se considerar a ação do homem, e em seguida, a geração do homem pelo homem"'. Contrariando toda a expectativa medieval cristã que via no corpo uma espécie de estorvo ao espírito, Tomás

\footnotetext{
${ }^{8}$ SAN BUENAVENTURA. Reducción de las ciências a la teologia, s/d (a), p. 639.

${ }^{9}$ TOMÁS DE AQUINO. Suma Teológica, s/d (c), p. 864.
} 
procura integrá-la completamente como parte essencial da realidade do ser humano, sendo que esta união se projeta na operação espiritual que é o conhecimento intelectual.

A Questão 117 da Suma teológica, dividida em 4 artigos, levantam questões pertinentes ao processo de formação do homem a partir de quatro perguntas básicas: um homem pode ensinar a outro? Um homem pode ensinar ao anjo? O homem pode agir sobre a matéria corporal, a partir de sua anima? A alma humana, separada da matéria, pode mover o corpo?

No que tange a primeira questão, Tomás de Aquino afirma que é impossível a um homem ensinar a outro, ou seja, causar-lhe a ciência no outro pois, partindo das ideias de Averróis, existe somente um intelecto possível em todos os homens, sendo que os mesmos aspectos inteligíveis estão em todos igualmente.

Desse modo, um homem pode comunicar ao outro a ciência que ele mesmo tem dentro de si. Tomas chega a concordar com a ideia de que a mesma ciência está no discípulo e no mestre, no entanto, sobre o fato de que existe somente um único intelecto, ele discorda. Isso implica que o homem pode adquirir a ciência tanto por um princípio interior, como por exemplo uma descoberta pessoal, como por um princípio exterior, quando se aprende algo de outro, sendo unânime o conhecimento de que todo ensinamento e toda disciplina se formam a partir de um conhecimento que já existe.

Na obra De Magistro, Tomas de Aquino procura expor a sua concepção sobre a relação entre ensino e aprendizagem, opondo-se às doutrinas de seu tempo. Isso nos leva à compreensão de que por trás de uma teoria pedagógica, se esconde uma antropologia filosófica e teológica muito rica.

Desse modo, o problema do ensino em nosso autor é proposto em sua doutrina sobre o conhecimento da relação entre ato e potência, afirmando que o ensino é "uma educação do ato; uma condução da potência ao ato que só o próprio aluno pode fazer" ${ }^{10}$. A função do professor nessa perspectiva é apresentar sinais e formas de fazer com que o aluno perceba o caminho de poder fazer por si só a educação do ato do conhecimento: "Nesse contexto, é altamente sugestiva a genial comparação da aprendizagem com a cura e a do professor com o médico"11.

No artigo 1 da obra De Magistro, o nosso autor procura questionar algumas concepções da época, como por exemplo, a ideia da existência de um único intelecto

\footnotetext{
${ }^{10}$ TOMÁS DE AQUINO. Sobre o Ensino, s/d (b), p. 21.

${ }^{11}$ TOMÁs DE AQUINO. Sobre o Ensino, s/d (b), p. 21.
} 
agente para todos os homens. No artigo 2, ele "aprofunda a discussão do ensino em oposição à aquisição de conhecimento por si próprio. E conclui a superioridade do ensino"12. Já no artigo 3, Tomás procura esboçar sua análise da questão sobre se o homem pode ser ensinado pelos anjos, tal como as formas dessa possibilidade, sendo que na compreensão tomasiana, o anjo não pensa através de uma atividade racional, como nós seres humanos, mas seu intelecto angelical tem acesso direto ao conhecimento, podendo prescindir completamente da razão. E por último, no artigo 4, Tomás demonstra as características do ensinar, perpassando pelos seus aspectos ativo e contemplativo.

\section{Conclusão}

Deste modo, ao término desta nossa reflexão sobre o pensamento desses autores medievais acerca de uma Filosofia da Educação na Idade Média, podemos ter a certeza de que a construção de um ideal educacional perpassa necessariamente sobre a ótica ontológica que caminha lado a lado as relações ética e políticas de uma sociedade.

Em outras palavras, os pensadores medievais pensaram os problemas sobre a educação a partir de sua compreensão sobre o que é o homem, se é composto de alma e corpo ou não, sobre o que ele pode conhecer e quem pode lhes transmitir ciência, sendo influenciado fortemente pela perspectiva e o embate que tanto ganhou força neste período histórico, a saber, a relação entre fé e razão, ou ainda, sobre aspectos que envolvem a Filosofia e a Teologia.

\section{Referências}

LAUAND, L. J. Cultura e educação na Idade Média. São Paulo: Martins Fontes, 1998. SAN BUENAVENTURA. Reducción de las ciências a la teologia. s/d (a).

HUGO DE SÃO VITOR Didascálion, Da arte de ler. Introdução e Tradução de Antônio Marchionni. Petrópolis: Vozes, 2001.

TOMÁS DE AQUINO. Sobre o Ensino. s/d (b).

TOMÁS DE AQUINO. Suma Teológica. s/d (c).

\footnotetext{
${ }^{12}$ TOMÁS DE AQUINO. Sobre o Ensino, s/d (b), p. 22.
} 